$$
\begin{aligned}
& M B \\
& 1 J \beta^{\circ} \\
& \frac{1}{1}
\end{aligned}
$$




\section{Executive Director}

Carlo Magnani

\section{Editorial Board}

Francesca Frassoldati (editor in chief); Alessandro Armando;

Daniele Campobenedetto; Valeria Federighi; Caterina Barioglio;

Federico Cesareo.

\section{Advisory Board}

Ash Amin; Tiziana Andina; Pepe Barbieri; Petar Bojanić; Alessandra Capuano; Pierre Chabard; Marco Cremaschi; Marco Dugato; Giovanni Durbiano; Franco Farinelli; Maurizio Ferraris; Hélène Frichot; Gevork Hartoonian; Felipe Hernandez; Sandra Kaji'O’Grady; Carlo Manzo; Carlo Olmo; Igor Marjanovic; Rahul Mehrotra; Juan Manuel Palerm Salazar; Gabriele Pasqui; Piero Ostilio Rossi; Andrea Sciascia; Felicity D. Scott; Jeremy Till; Stephan Trüby; Ilaria Valente; Albena Yaneva; Zhang Li.

\section{Contacts}

For any question regarding submission to Ardeth or reviews, please write to redazione@ardeth.eu

For any further question, please write to info@ardeth.eu

Articles and calls for papers are available on www.ardeth.eu

\section{Production}

Politecnico di Milano, DAStU (Dipartimento di Architettura e Studi Urbani)

Politecnico di Torino, DAD (Dipartimento di Architettura e Design)

Università IUAV di Venezia, DCP (Dipartimento di Culture del Progetto)

Università di Roma La Sapienza, DiAP (Dipartimento di Architettura e Progetto) 


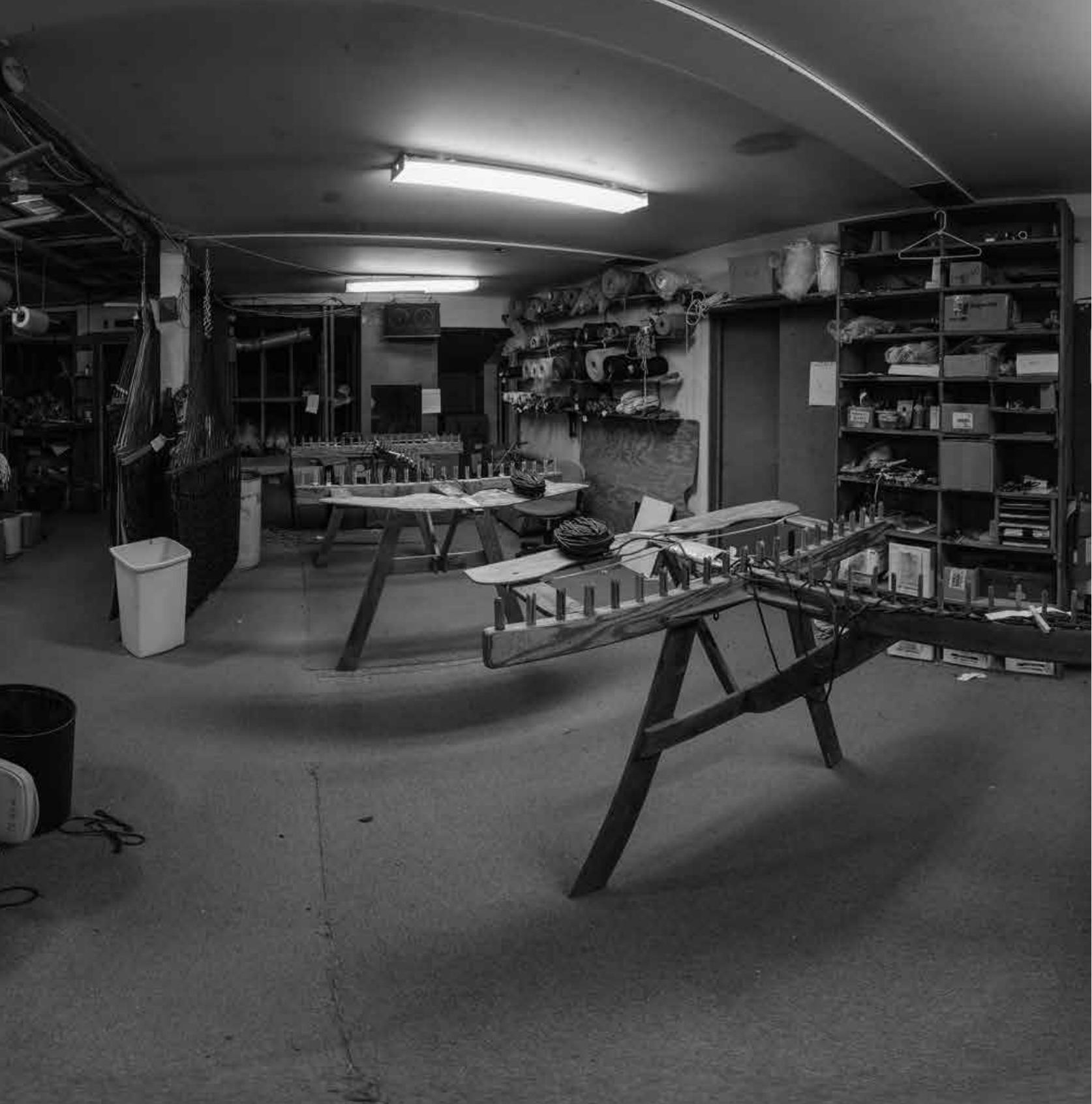




\section{Ardeth \#05 contents}

5 The Innovation of the Other The Editorial Board of "Ardeth"

15 Editorial. Political Innovation Andrés Jaque

27 Principles of Construction. An Ontology of Design Enrico Terrone

43 Innovazione: quale miglioramento? Pratiche di costruzione sociale Micol Rispoli

57 The Production of Project. A Subversive Guide to the Subject of Innovation

Camilo Vladimir de Lima Amaral

79 Parametrizzare la mente dell'architetto. Il caso di Tour Bois le Prêtre Grazia Pota

97 Faxing Architecture. Aldo Rossi's Transnational Practice, 1986-1997

Sebastiano Fabbrini

119 Ghost Islands

Laurent Gutierrez, Valérie Portefaix

133 A Panoptic Cartography of Remote Sensing Marco Ferrari
145 La vita delle macchine. Improvvisazione materiale creativa attraverso trasformazioni urbane a Barcellona-22@

Daniel Torrego Gómez, Miguel Mesa del Castillo Clavel

165 Data (Centers) Controversies Ippolito Pestellini Laparelli

185 Atmospheric Infrastructures to Deal with the Toxic Air in a Common World Nerea Calvillo

199 On Interference. Designing Strange Life Forms that Don't Always Listen Lydia Kallipoliti

213 Innovation as Loss? In Dialogue with Three Contemporary Practices Andrea Alberto Dutto

221 Integrating AI and Deep Learning within Design Practice Processes: XKool Technology Edoardo Bruno

228 Reviews

235 Ardeth \#07 Jörg H. Gleiter 
archi-
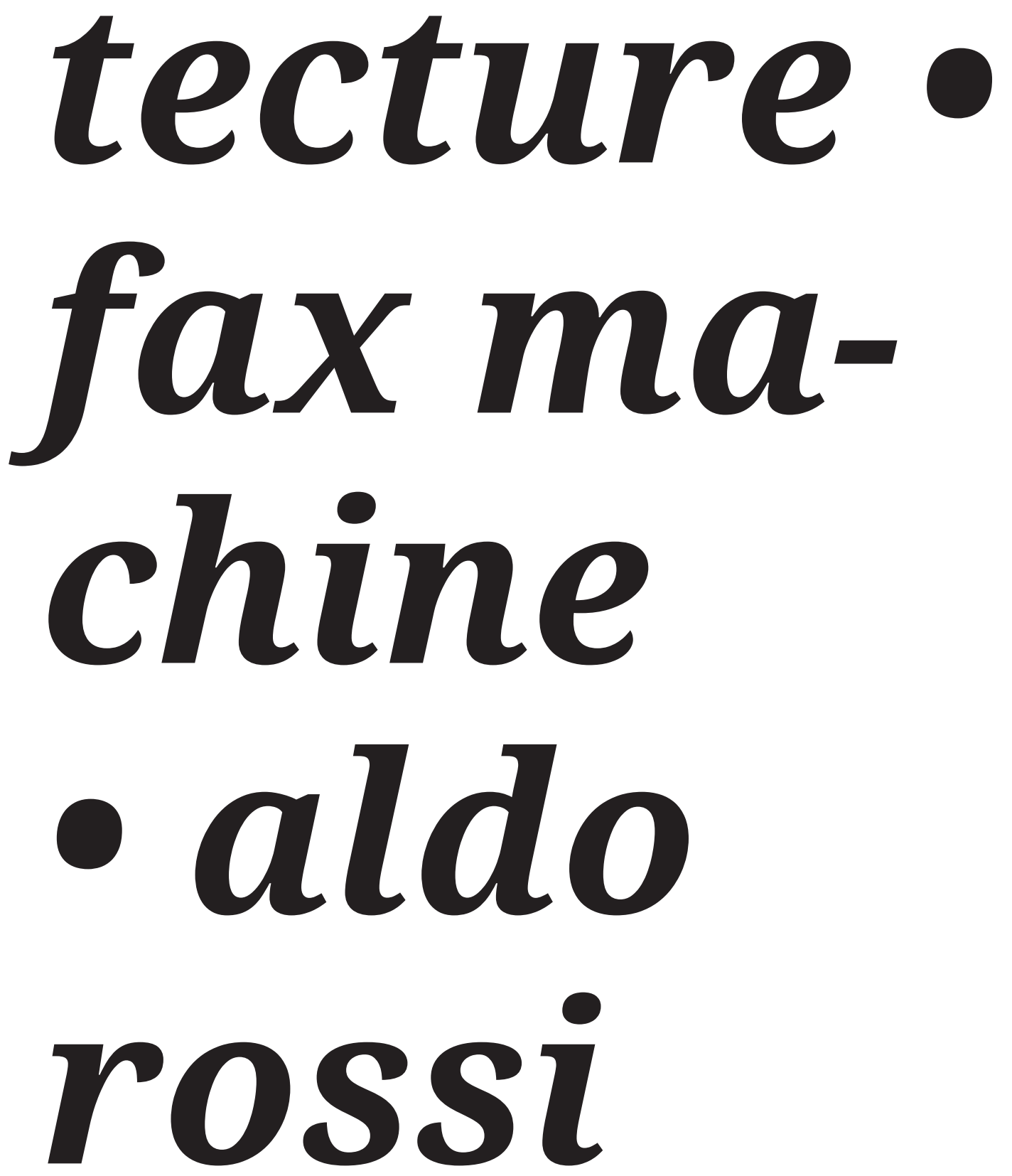


\section{Faxing Architecture Aldo Rossi's Transnational Practice, 1986-1997}

Sebastiano Fabbrini

Abstract

In 1986, Aldo Rossi opened a satellite office in New York City to oversee his first major design commissions on the other side of the Atlantic. This moment marked a transition from traveling to establishing a permanent presence in the United States. And, more importantly, it turned Rossi's practice into a transnational organization. It is fair to say that most of his subsequent projects were developed on the Milan New York axis. The trait d'union was the fax machine, which allowed materials and ideas to be exchanged with an unprecedented level of immediacy. This research paper explores how faxing impacted the production of architecture within this decentralized system, intersecting multiple key topoi of the architectural discourse of the time. While the literature on Rossi tends to focus on the work and the loud theoretical apparatus that accompanied it, his (largely unexplored) American archive compels us to engage with the process of working and the silent technological apparatus that made it possible.
Affiliation

Università luav di Venezia, Dipartimento di Culture del Progetto

Contacts: sfabbrini [at] iuav [dot] it

Received: 25 March 2019

Accepted: 02 September 2019

DOI:

10.17454/ARDETH05.07

\section{ARDETH\#05}




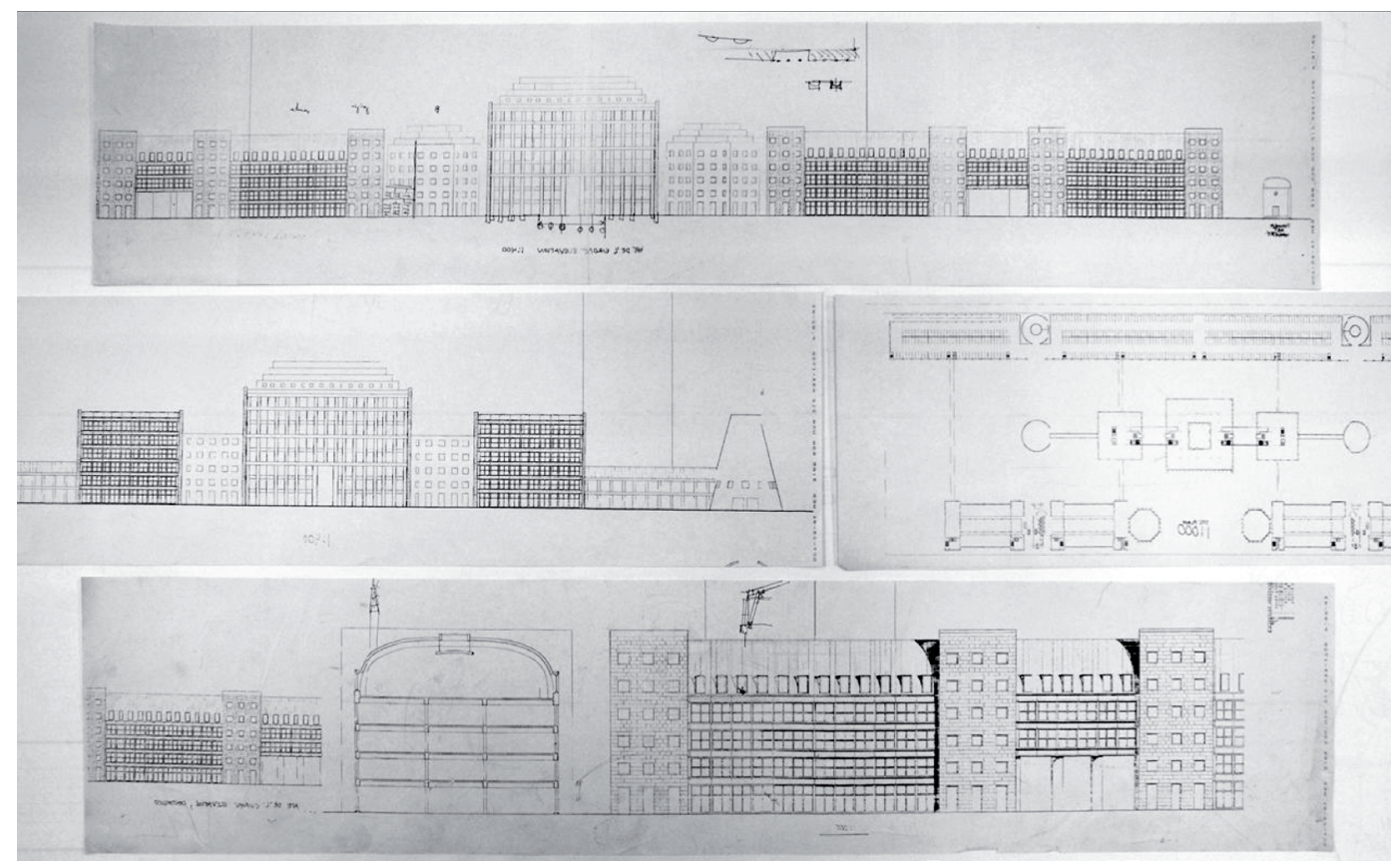

Fig. 1 - Aldo Rossi's fax transmissions on the Milan - New York axis, 1991 Canadian Centre for Architecture, Aldo Rossi Fonds, Project: Eurodisney. (c) Eredi Aldo Rossi, courtesy Fondazione Aldo Rossi.

1 - This set of photographs is held in the Archive of the MAXXI (Rome), Fondo Aldo Rossi: Materiale Fotografico e Video.

\section{$\underline{\mathbf{2} \text { - In addition to }}$} the satellite office in Manhattan, Rossi opened two shops in The Hague (1987) and Tokyo (1989) to oversee local projects. These dynamics are detailed in the website of the Fondazione Aldo Rossi.
The studio

Two sets of photographs, both taken at the turn of the 1980s, offer a good introduction into the relation between Rossi's workspaces in Milan and New York. The first is a series titled "Studio di Aldo Rossi," made by Luigi Ghirri, renowned photographer and friend of the architect: it includes both the studio in Via Maddalena, where Rossi operated from 1969 to 1989, and the studio in Via Santa Maria alla Porta, where he spent the last seven years of his career. Widely published and exhibited, Ghirri's photographs played a pivotal role in constructing the particular imagery of Rossi's Milanese studio (Costantini, 2016). The second is a set of pictures of the Manhattan office taken by Rossi himself, with a basic compact camera. ${ }^{1}$ They were meant for private use and recorded the situation in the satellite office shortly after its inauguration. The interaction between these environments is key to understanding the last decade of Rossi's career. While he had already worked in numerous counties, the opening of the American office gave a different structure to these centrifugal forces, setting in motion a truly transatlantic design process. ${ }^{2}$ The turning point was not operating and building all over world, but rather developing the projects in a transnational framework. 
Firstly, there is a semantic divergence: the terms studio and office reflect two dissimilar approaches toward the production of architecture (Buren, 1979; Jones, 1995; Van Meel, 2000; Martin, 2003; Agamben, 2017). In Ghirri's photographs, the studio is presented as Rossi's wunderkammer - a highly aestheticized environment, full of objects of affection and devoid of both laborers and machines. As noted by Morris Adjmi, the American architect who helped create and then directed the Manhattan office, the Milanese space was indeed very low-tech: all the drawings were done by hand, Rossi and his collaborators did not use computers and, apparently, there was only one telephone in the entire studio. ${ }^{3}$ According to one of Rossi's Italian employees, the first computer was installed in the studio of Via Maddalena around 1988: it was a "bulky Macintosh" and was used only for writing, not drawing. ${ }^{4}$ One of the key aspects of this curated environment is the underlying sense of domesticity it conveys. In a short piece written on the occasion of the 1990 Pritzker Prize ceremony, Kurt Forster mentioned visiting Rossi's “apartment and studio," both located in a nineteenth-century enclave of Milan, and alluded to the "haunted familiarity" of the architect's workspace (Forster, 1990). He went as far as to compare it to the residence of a latter-day John Soane.

But Ghirri's photographs evoke a different sense of familiarity, with a more intimate and sensuous undertone. Particularly interesting is the image of Rossi's bed in the studio of Via Santa Maria alla Porta. Both the presence of a bedroom and the fact that a photographer like Ghirri would shine a light on it speak to a very specific understanding of the environment of the studio. Bringing to mind Leo Steinberg's reflections on the flatbed picture plane, Ghirri's image seems to suggest a continuity between the bed and the desk - the surfaces associated with making (Steinberg, 1972). Not only the bed is surrounded by drawings, hung on the blue walls, but multiple rolled-up drawings are placed on its horizontal surface, above the white sheets. Interestingly, some of these drawings appear to be faxes. In fact, while this technology is commonly associated with corporate milieus, the development of faxing went hand in hand with a trend towards the domestication of labor. For example, roughly a third of all new businesses registered in Europe and the
3 - Morris Adjmi, interview by the author, 10 April 2016.

4-Conversation with Saverio Fera at the conference Aldo Rossi: Perspectives from the World, Politecnico di Milano, 12 June 2018. Fera worked in Rossi's Milanese studio from 1987 to 1991.

\section{The turning point was not operating and building all over world, but rather developing the projects in a transnational framework.}




\section{While this technology is commonly associated with corporate milieus, the development of faxing went hand in hand with a trend towards the domestication of labor.}

Fig. 2 - Aldo Rossi's office in New York City, 1988

Museo delle Arti del XXI Secolo, Fondo Aldo Rossi, Materiale fotografico e video. (c) Eredi Aldo Rossi, courtesy Fondazione Aldo Rossi.
United States in 1989, right around the time of Ghirri's photoshoots, operated out of a home. And the fax machine, whose sales grew by $2000 \%$ over the course of the 1980s, was a key factor in this reconsideration of the home as a place of business, at the dawn of the digital revolution (Quinn, 1989).

The interplay between the bed and the drawings also speaks to a broader iconographic horror vacui, which characterized the entire representation of the Milanese studio. In Ghirri's photographs, even the bookshelves are wrapped in drawings, some of which (again) show the typical marks of faxing. What is not visible, however, is the process behind such overload of drawings. Only the footprint is on display, not how it was made or who made it. While the studio appears to be full of heterogenous objects - souvenirs, marionettes, porcelains and several other things describable as toys - there are no machines, and most of the manual drawing tools are confined to a secondary room. In this space, which Ghirri does not photograph, the tools are hung on the wall, next to a variety of other objects. There is no solution of continuity, or differentiation in treatment, between a pencil sharpener and a wooden statuette, or between a compass and an exotic shell. Even in the equipment room, it is impossible to draw a line between tools and toys.

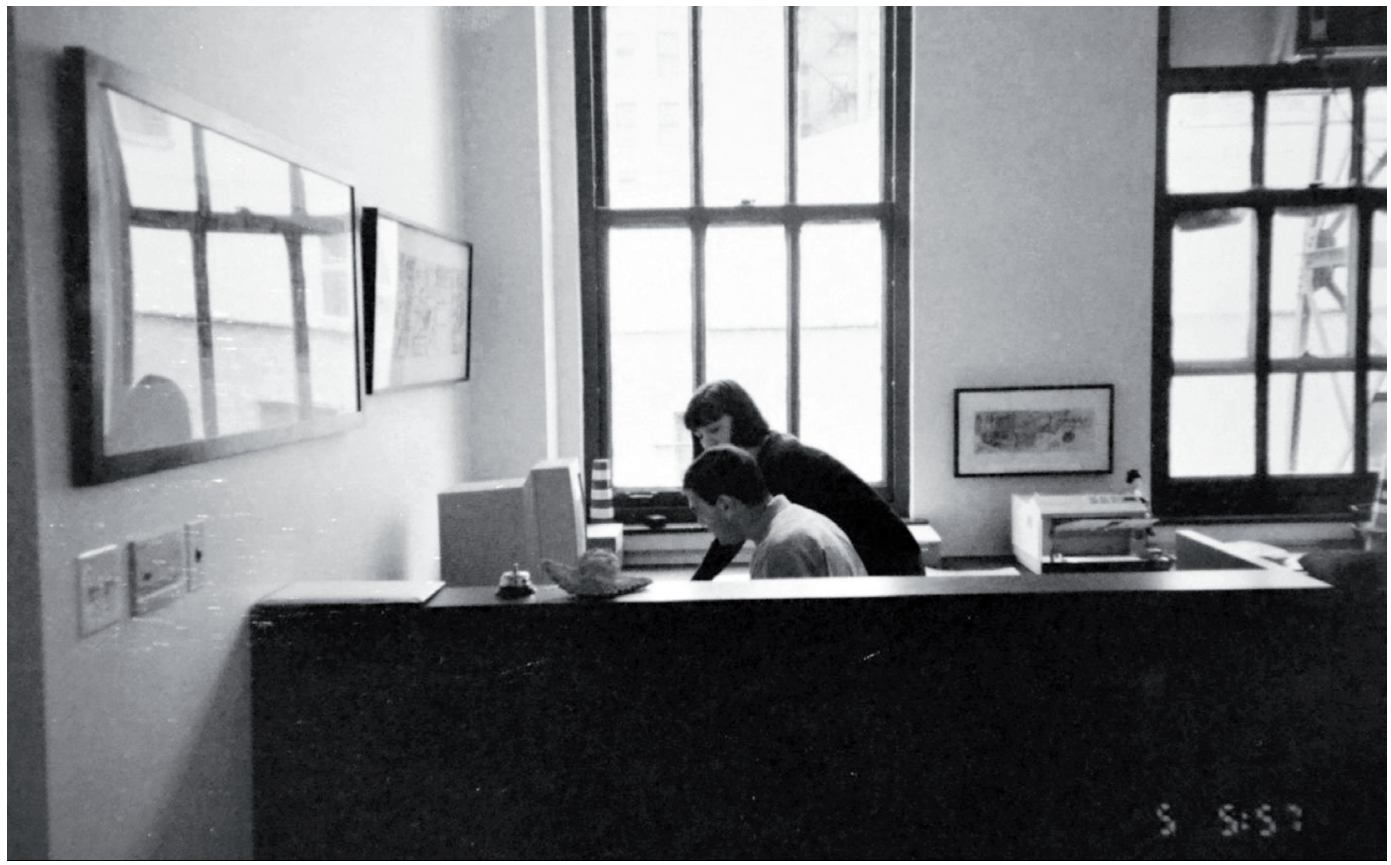


In New York, things were presented in a substantially different way. First, it is easy to see that the photographs taken by Rossi in 1988 were less choreographed than Ghirri's pictures. They were not meant to be published and, in fact, no images of the satellite office were ever made public. The opening picture, the one showing the entrance, is particularly noteworthy. The initial contact with the office is through a room framed by machines, including a computer, a printer and a fax machine. And this space is populated by laborers, photographed while being busy in front of a computer screen. Unlike Ghirri's photos, this image documents work being done, showing both the people and the machines involved in the process.

Clearly, Rossi was not the first European architect to branch out in the United States. In fact, one could analyze the genealogy of this phenomenon throughout the twentieth century, culminating in the opening of OMA's office in New York in the year 2000. But Rossi's move shines a light on a particular juncture in this historical trajectory - just before the advent of the digital age, as the United States were approaching the end of the Reagan era and Europe had just launched the project of a new single market.

Douglas Moreland, an architect who worked as a project manager for Disney and collaborated with Rossi in the early 1990s, used the terms "creative" and "corporate" to explain the structure of the Manhattan office. ${ }^{5}$ Hypothesizing an ideal spectrum of environments from creative to corporate, he placed Rossi's office near the creative end of the spectrum, on the opposite side of his own office at Disney. Looking at it from a different perspective, Adjmi described the New York office as being informed by "an American approach," pointing to the application of advanced technologies, as well as the overall organization of the workspace, and contrasting it with the Milanese state of affairs. ${ }^{6}$ Analyzing Rossi's photographs, however, this office can hardly be associated with the organizational logic and the physiognomy of American corporate architecture (or, at least, with its stereotypical imagery) and, even though the work was mostly computerized, no one would interpret it as an "information age interior” (Martin, 2003; Harwood, 2003). Besides, as noted by New York architect Richard Hayes, Rossi's office was located in a historical building near the Flatiron

\section{Analyzing Rossi's photographs, this office can hardly be associated with the organizational logic and the physiognomy of American corporate architecture.}

6 - Morris Adjmi, interview by the author, 10 April 2016.

\section{The same space was perceived and described in different ways by a number of individuals who came in contact with Rossi.}


7 - Conversation with Richard Hayes at the conference The Tools of the Architect, Technische Universiteit Delft, 23 November 2017.

8 - Morris Adjmi, interview by the author, 10 April 2016.
Fig. 3 - Global Art Fusion: Faxing performance at the Vienna Museum of Modern Art, 1985.
District, in Midtown Manhattan - an area described as having a distinctly "European flair." Clearly, assigning labels is not the point. What is interesting is the fact that the same space was perceived and described in different ways by a number of individuals who came in contact with Rossi, depending on their professional background and, sometimes, their nationality. Therefore, in an attempt to understand the interaction between Milan and New York in Rossi's practice, it may be more productive to focus on what the two spaces produced. As it turns out, this interaction was based on a specific division of labor, which involved both the modes of production and the content being produced. Not only the work was done by hand on one side of the Atlantic and by computers on the other side. As pointed out by Adjmi, there was also a distinction in the type of work that was assigned to Milan and New York. ${ }^{8}$

For example, Milan focused primarily on preliminary sketches and final presentation drawings, while New York produced most of the technical drawings. Milan dealt with façade design, while New York took care of massing and logistics, and so on. From this perspective, different expertise and working methodologies came to be organized in a framework where each center was set up to produce specific things with specific technologies. The technology that kept everything together was the fax machine.

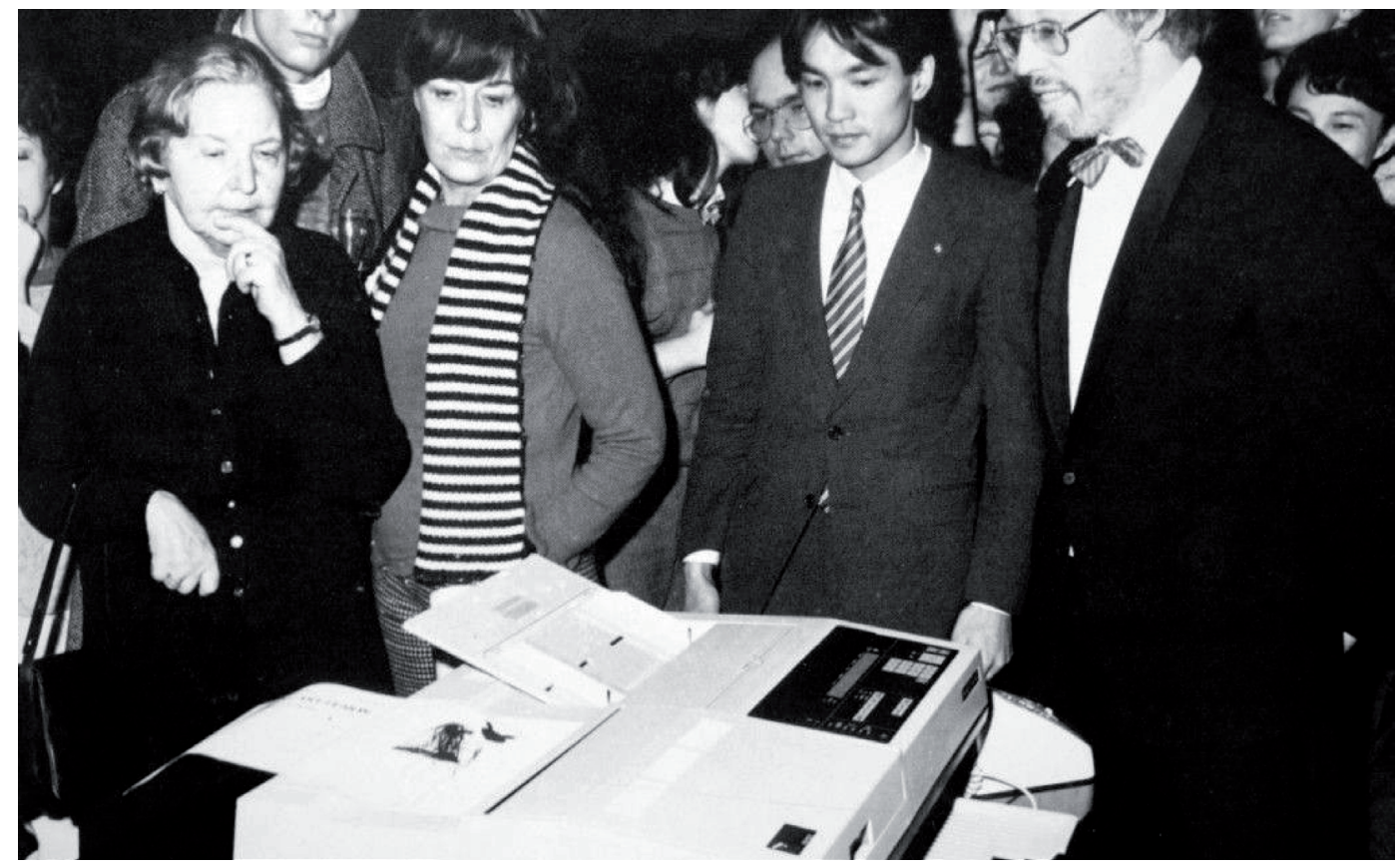


The politics of faxing

What was the state of the discourse on faxing when this process was set in motion? To give some context, few months before the opening of Rossi's satellite office in New York, Andy Warhol collaborated with Joseph Beuys and Kaii Higashiyama in a project titled Global Art Fusion. Presented as "fax art," this project involved sending a fax with drawings of all three artists within 32 minutes around the world - from Dusseldorf via New York to Tokyo, and finally Vienna, where the fax was exhibited at the Palais Liechtenstein Museum of Modern Art (Warhol et al., 1986). This fax was declaredly intended as a symbol of peace, against the backdrop of the global tensions caused by the Cold War during the 1980s. In the same period, experimental architectural practices like ARX started to talk about a "fax design process." And the idea was given a good amount of publicity by an issue of ANY devoted to "electrotecture" in 1993 (Davidson, 1993). At the same time, this technology was starting to be recognized for its political potential, especially in Europe. For example, in November 1989 (the same month of the fall of the Berlin wall), the Council of Europe launched a program called Fax! The objective was to produce a multi-lingual newspaper, created by students from all over Europe, using only fax machines. At the core of this project was the conviction that this new communication technology was more than a means towards an integrated Europe: by its very nature, faxing was viewed as an embodiment of that process of integration.

And this was not an isolated case. It was followed by similar publications, such as Le Petit Faxeur in France and Lingua Fax in Spain, just to name a few examples. On a larger scale, faxing was also at the center of a project promoted by several cultural institutions throughout Europe, on the theme "What does being European mean to you?”. ${ }^{9}$ In all of these instances, faxing did not just provide the infrastructure through which this debate could unfold: it was approached from a political point of view, as a technology that in itself conveyed a specific message regarding the dissolution of national borders.

This idea was taken one step further by American artist Lillian Bell: on the occasion of the 1992 Earth Summit in Brazil, she designed an installation for the
9 - In 1990, Telecoopicem, an education network based in France, organized a project in which French and Spanish students were asked to send to each other faxes explaining what it meant to be Europeans.

\section{Fax was declaredly intended as a symbol of peace, against the backdrop of the global tensions caused by the Cold War.}




\section{The importance of faxing in the early debate on the art and architecture of the electronic age was quickly overshadowed by the advent of the computer.}

display of faxes sent by artists from around the world, and this led to the creation of a network called F'AXis, which included 220 artists from 29 countries. Bell imagined her fax machine as a gallery without walls: "Fax is a new technology for duty-free and boundary-free art, and represents the abolition of time and space” (Bell, 1994).

The importance of faxing in the early debate on the art and architecture of the electronic age was quickly overshadowed by the advent of the computer, and everything else that came with it. A key aspect of faxing was that, while participating in the mechanization of design, it did not quite belong to the digital world: the fax machines used by Rossi's generation were mostly based on analog technologies. While the computer was related to a new digital age, the fax embodied the swan song of an analog world that still had paper as its indispensable medium.

In one of the most comprehensive studies of this technology, Jonathan Coopersmith presents the history of faxing as a trajectory with a clear beginning and end (Coopersmith, 2015). His survey begins in 1843 with a patent written by Scottish watchmaker Alexander Bain, and ends in 2000, when a standards committee for facsimile merged into a committee on data transmission standards. The first year represents legal recognition of facsimile as a concept. The latter, its bureaucratic absorption into computer-based communications.

However, most historians of technology agree that the fax machine truly became a commodity only in the 1980 s, as a result of the formation of a system of international standards, that guaranteed compatibility and allowed faxing to function properly on a global scale. Hence, the rise and fall of the fax machine is generally inscribed in a period of less than two decades, a period corresponding more or less to the lifespan of Rossi's transatlantic practice. By the time of the architect's death in 1997, faxing had just started to lose its primacy and independent existence to digital communications in the form of the internet, the world wide web, PDF, cell-phones and other technologies. In 1994, Liz Farrelly described faxing as "the last form of hardcopy messaging in an increasingly computerized world" (Farrelly, 1994). Since faxing operated in a paper-based dimension and was still dealing 
with hardcopies, a key aspect of this mode of communication was its printing technology. What made faxing possible was the advent of thermal printing - a technology that relied on a particular type of paper, coated with a chemical that changed color when exposed to heat.

The particularity of this so-called "thermal paper" is its extreme lack of durability. For example, upon opening a beginner's guide to fax machines published in 1988, one of the first paragraphs reads: "A faxed document left on the dashboard of a car on a hot summer day will turn completely black” (Fishman, King, 1988). Regardless of where the document was left, however, not long after the printing, the image-forming coating tended to detach from the medium, slowly destroying the document. In other words, the drawing self-destructed after a few years. Which is why faxes are not accepted by most archives. Faxing architecture, therefore, meant operating in an ephemeral and non-archivable dimension. From this perspective, it is interesting to note that the cult of the drawing - one of the premises of Rossi's success, especially in America - was accompanied by the development of a mode of communication that literally disintegrated the drawing itself.

Just like with fiscal receipts, the only way to preserve a faxed document is to make a photocopy. In the early 2000s, after acquiring a significant portion of Rossi's collection, the Canadian Centre for Architecture started to address this issue. And this led to a peculiar condition within the Rossi archive. In fact, many documents have now multiple versions: the fax, which is usually in a state of decay, and - attached to it with a paper clip - a photocopy, which often constitutes the only legible record. On the occasions when the so-called original-the piece of paper that was faxed in the first place-is also available, then the same object can be seen on three different mediums. The whole operation is always announced by a clear sign on the photocopy: "Photocopie faite à partir d'un fax dans le fonds Aldo Rossi au CCA.”10

Rossi's faxes were often accompanied by a rather articulated piece of communication infrastructure: the cover sheet. In this case, an entire page was devoted to defining the details of the fax transmission and describing its content. Next to a multitude of adminis-
10 - Take as an example the documentation related to Rossi's housing project in Mount Pocono, Pennsylvania, 1988 - Archive of the Canadian Centre for Architecture (Montreal), Aldo Rossi Fonds: Projects.

\section{Faxing architecture, meant operating in an ephemeral and non-archivable dimension.}


11 - Ibid.

12 - This document

is held in the

Archive of the Getty

Research Institute

(Los Angeles), Aldo

Rossi Papers: Drafts

and Writings.

\section{A drawing sent via fax, by definition, cannot be an original drawing.}

trative options, there was a particularly problematic checkbox: it said "Original Drawings." When drawings were included in a fax transmission, the sender would check this preset box, but would usually cross out the word "Original." 11

This detail is significant because it reveals an understanding of the complicated position occupied by the fax vis-à-vis the concepts of the copy and the original. A drawing sent via fax, by definition, cannot be an original drawing: it's a facsimile, a copy of something else. But, given the complexity of the transmission process, faxing required to think about this dichotomy in a different way, reflecting on the oxymoronic possibility of an original facsimile - a contradiction that would later be exploded by the digital revolution. Building on Walter Benjamin's work, Bruno Latour has addressed this conundrum by suggesting that the aura of originality is not immobile, but can actually "travel" and "migrate to the newest and latest copy" (Latour, 2010). In Rossi's case, it is worth noting that, while constantly addressing the issue of reproduction in his writings and design works, he operated through a technological apparatus that fundamentally challenged the notion of originality.

In the American context, the Teatro del Mondo is a particularly fitting example: after the international success of the 1980 Biennale (First Lady Nancy Reagan went as far as to promote a diplomatic mission to bring the floating structure to the other side of the Atlantic), Rossi started to include replicas of the Venetian theater in many of his American projects, from the campus of the University of Miami to the projects for Disney (Ornaghi, Zorzi, 2015). This act was part of a broader approach to design, whereby a limited number of forms extracted form a few selected projects - such as the Teatro del Mondo, the Modena Cemetery and the Gallaratese - could be constantly reproduced and reassembled in different milieus. Among other reflections on originality and repetition in Rossi's writings, this sentence annotated on a loose piece of paper in 1980 is particularly fitting: "The original - real or presumed - will be an obscure object that will identify with the copy.”12 
Fig. 4 - Cover of the Council of Europe's booklet of The Fax! Programme, 1989.

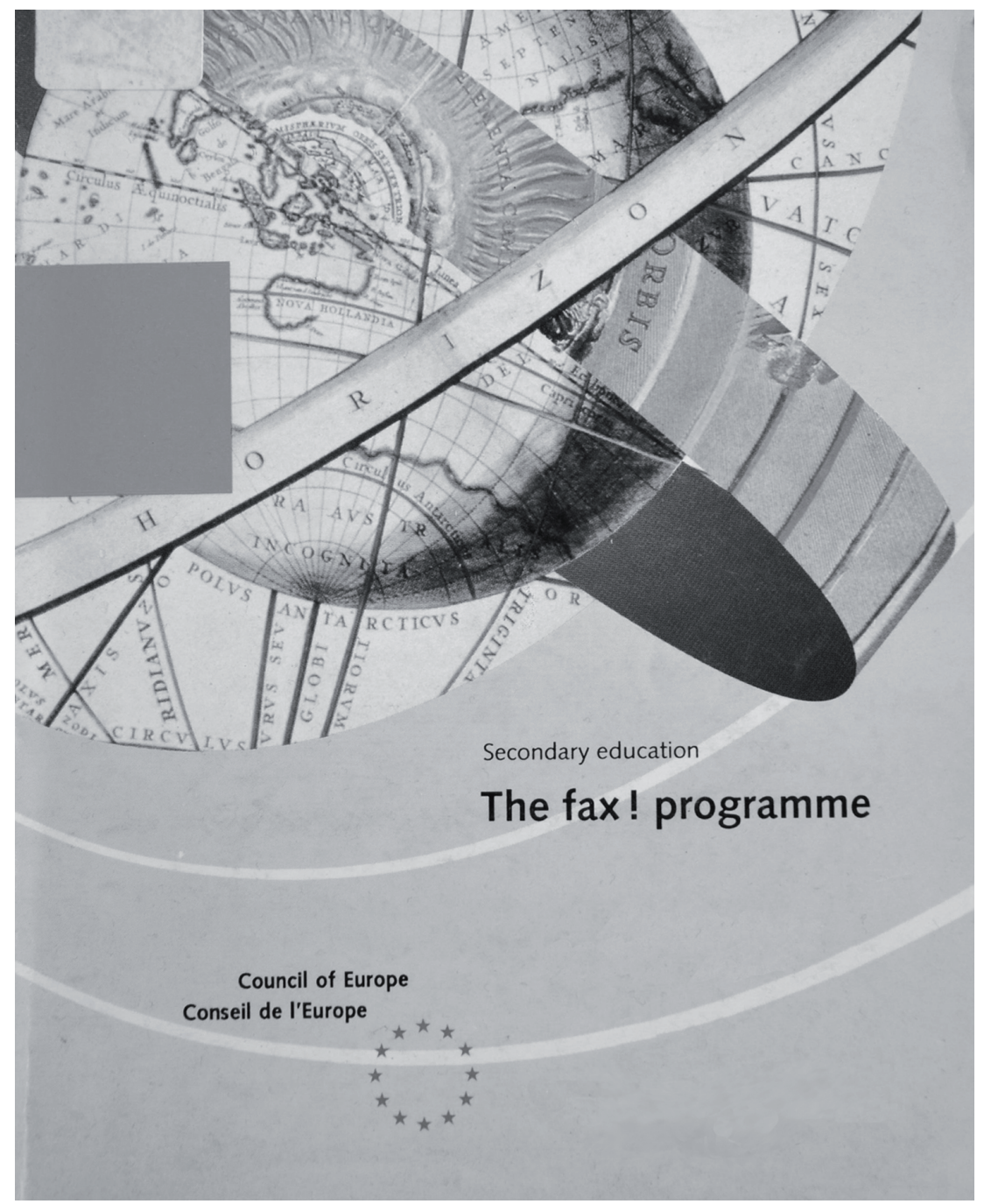




\section{Due to the}

restrictions of the

format, faxing

a plan was the

most complicated

operation, and

usually required a good deal of cutting and pasting.
The logic of the collage operated, in the everyday innerworkings

of Rossi's

transnational

practice.
Working through fax machines

As a whole, the archival material held by the CCA - both the surviving faxes and their photocopies - is key to understanding how this technology impacted the design process within Rossi's practice. The most evident effect involves the format of the work. In fact, while faxing imposed a limited width to all documents, their length was virtually unlimited, inducing what can be described as a scroll effect. The drawings had to be done on long and narrow scrolls, that were sometimes taped together in order to create wider documents. And, clearly, these format limitations had a significant impact on the types of drawings that were produced. Anyone who has ever laid out an architectural drawing knows that a long and narrow sheet of paper is better suited for an elevation or a section, rather than a plan. In fact, due to the restrictions of the format, faxing a plan was the most complicated operation, and usually required a good deal of cutting and pasting. That is why plans were sometimes set aside in favor of other drawings - especially axonometric drawings - that could communicate most of the essential information, while being squeezed into a narrower sheet. But, overall, the undisputed protagonist of this scroll-like format was the façade - shining a new light on the "façadism" that is commonly associated with postmodern architecture.

Many faxes included notes and signs, indicating how separate drawings were to be juxtaposed and taped together after the printing. In this respect, the process of cutting and pasting that followed some of these fax transmissions brings to mind Rossi's renowned collages, such as the collage The Analogous City (Szacka, 2014). And, again, the breakdown of drawings into fragments amenable to be faxed back and forth brings to mind what is often described as the essence of Rossi's architecture - an additive compositional process based on a limited number of "pieces" and "parts" (Bonfanti, 1970). While most studies have focused on the poetic results of this process, the logic of the collage operated also on a very prosaic level, in the everyday innerworkings of Rossi's transnational practice.

Among other examples, this dynamic can be related to David Hockney's contemporaneous exploration of new methods of image reproduction, which included making composite photographs with a polaroid camera and investigating the integrity of "surface" with a 
color copier. In the late 1980s, he faxed entire exhibitions to galleries in San Paolo, Bradford and Tokyo: huge images made from up to $288 \mathrm{~A} 4$ sheets were fed into a fax machine at his studio in Los Angeles, to rematerialize half way around the world and be assembled in front of an audience (Melia, 1995).

Even though it was never completed, Rossi's project for a hotel at Euro Disney, in Paris, represents an interesting case study. ${ }^{13}$ Started in 1988, the project was entirely developed on the Milan - New York axis, sending faxes back and forth. In this case, the surviving documents clearly show that the logic of the collage was applied to both the pre-fax and the post-fax stages of this transatlantic interaction. On the one hand, several preliminary sketches were done by cutting, pasting and taping multiple hand-made drawings - a stratification of pieces of paper with irregular shapes and varying sizes. On the other hand, as already noted, the received faxes often needed to be taped together in order to recompose larger drawings. In both cases, the marks of this operation are quite noticeable, usually in the form of small pieces of yellow adhesive tape or masking tape.

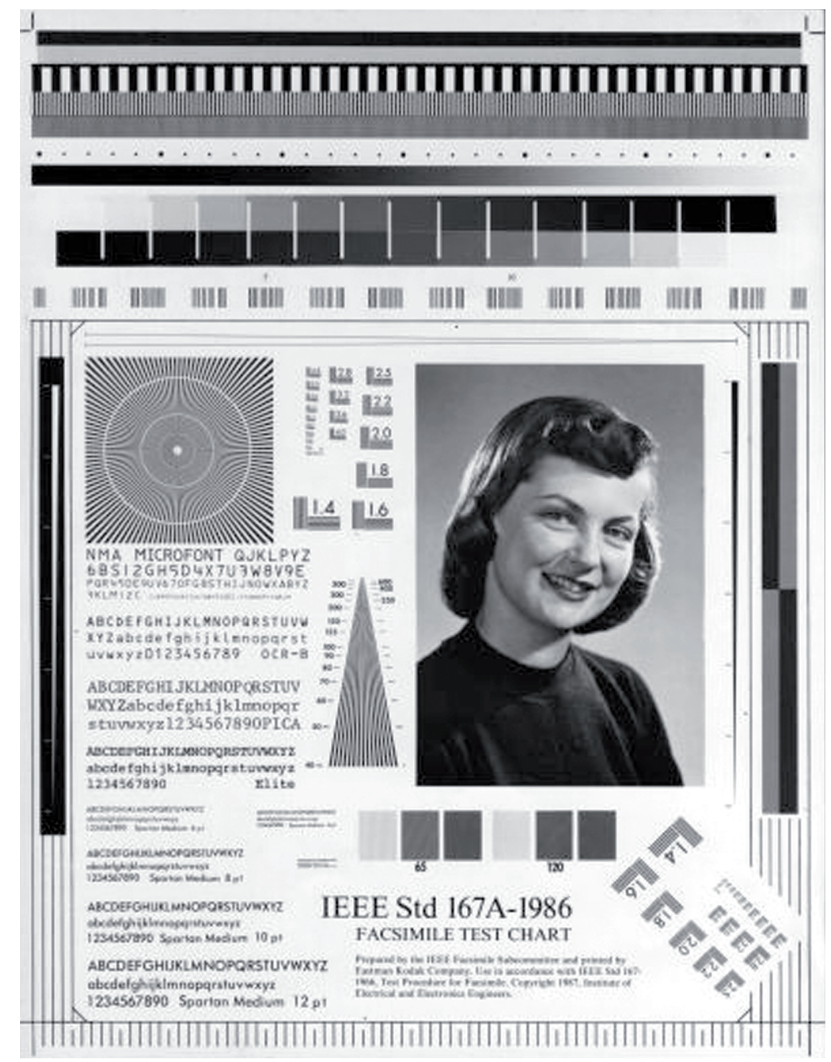

13 - This documentation is held in the Archive of the Canadian Centre for Architecture (Montreal), Aldo Rossi Fonds: Projects.

\section{The construction of a faxable document also relied on a few devices designed to spell out the terms of the transmission process.}

Fig. 5 - CCITT fax test chart 167A, 1986. 
14 - Fax sent to

Rossi by his Amer-

ican collaborators,

8 October 1991

- Archive of the

Canadian Centre for

Architecture (Mon-

treal), Aldo Rossi

Fonds: Projects.

15 - In The Architecture of the City. Rossi defines the locus as "a relationship between a certain specific location and the buildings that are in it; it is at once singular and universal."

\section{The document} existed both in New York and Milan: an object that existed in more than one locus.
The construction of a faxable document also relied on a few devices designed to spell out the terms of the transmission process. The simplest of these devices was the so-called fax memo note, a small piece a paper that provided space for basic information like dates, locations, names of the sender and the receiver, number of pages, as well as short messages. Since these notes were attached to the top of the transmitted documents, they also operated as one of the layers of Rossi's collages. For example, in the Euro Disney project, the drawings are preceded by a note indicating that the material had been exchanged between "I Discepoli" and "Il Maestro." The message reads: "Speriamo di essere dei buoni allievi." ${ }^{14}$ In addition to illustrating the type of relationship that existed between Rossi and his collaborators, the memo notes are also key to establishing the geography of the drawing. In fact, there are always two entries marked as "Location." And this does not simply indicate that the document went from New York to Milan, as in a traditional shipment. It should be read as an indication that the document existed both in New York and Milan: an object with multiple locations. Or, using a Rossian term, an object that existed in more than one locus. ${ }^{15}$

This has to do, on the one hand, with the intangible nature of the transmission process: a document that goes through a fax machine does not physically leaves its location, while at the same time appearing (in the form of a facsimile) somewhere else. And, on the other hand, it has to do with a condition of nonstop interaction, where the same object is sent back and forth so many times - adding comments and making adjustments - that no one can really tell the recipient from the sender.

Reflecting on these dynamics in the early 1990s, British designer Paul Elliman went as far as to define faxing as a four-dimensional art: "It is like being in two places at once" (Poynor, 1997). In the aforementioned issue of $A N Y$, Cynthia Davidson took it even further: "Electrotecture calls for the refiguring of the very terms that define architectural theory and practice. When speed reaches a certain point, time and space collapse and distance seems to disappear. The very conditions of spatio-temporal experience are radically transformed. At this point, does architecture finally become immaterial?” (Davidson, 1993). 
The aesthetics of international standards

From the perspective of this particular condition of continuous dematerialization and rematerialization, faxing provides a different way to approach another concept that played a key role in Rossi's theory of architecture: the concept of scalability. A constant concern during this transatlantic exchange was the scaling of the faxed materials, as evidence by a multitude of handwritten specifications on the drawings. ${ }^{16}$ In a very literal sense, the challenge was to keep control over the scale of objects that were repeatedly dematerialized and recreated in different locations. It is safe to assume that this is not what Kurt Forster had in mind when writing about "Rossi's uncanny shifts of scale" (Forster, 1990).

For example, a note written by Adjmi on the cover sheet of a fax sent to Milan in 1988 reads: "La scala di tutto è lo stesso.” ${ }^{17}$ This message written in all caps and poor grammar, indicating that all the drawings within that fax transmission had the same scale, is emblematic of an underlying struggle to overcame a multitude of communication obstacles. Even though faxing required specific formats, the fax machines used in America did not operate with the same type of paper as the machines used in Europe. The documents fed into a fax machine in New York had the width of a US Legal page (8.5 inches), but came out in Milan with the width of an A4 page (21 centimeters), and vice versa.

Not only there was a dimensional gap between these page sizes. On a deeper level, the two machines responded to different units of measure. And, looking at this issue from a political perspective, this divergence highlighted a tension between state-level rules and international rules: while the Legal format was defined by the American National Standards Institute, the A4 format came out of the International Organization for Standardization (Bartlett, 1984; Kinross, 2009).

Most historians of technology point to two intertwined phenomena to explain the (short-lived) success of the fax machine: the deregulation of telecommunications that took place in several Western countries throughout the 1970s and, even more importantly, the adoption and implementation of international standards in the 1980s, which enforced compatibility on a global scale. As noted by Jonathan Coopersmith, developing

\author{
16 - Take as an \\ example the docu- \\ mentation related \\ to Rossi's housing \\ project in Este, \\ Italy, 1994 - Archive \\ of the Canadian \\ Centre for Archi- \\ tecture (Montreal), \\ Aldo Rossi Fonds: \\ Projects. \\ 17 - Fax sent to \\ Rossi by Adjmi, \\ 24 March 1988 \\ - Archive of the \\ Canadian Centre for \\ Architecture (Mon- \\ treal), Aldo Rossi \\ Fonds: Projects.
}

\section{The two machines responded to different units of measure. Looking at this issue from a political perspective, this divergence highlighted a tension between state-level rules and international rules.}




\section{The process of} standardization

that allowed the fax machine to become a widespread commodity went hand in hand with the promotion of a specific aesthetic. this technology was essentially a "game of standards" (Coopersmith, 2015).

The driving force behind this process was the CCITT (International Consultative Committee on Telegraphy and Telephony) - a specialized agency of the United Nations responsible for regulating international communications. A key component of this regulatory effort was the production of a series of documents called "fax test charts" (McConnell et al, 1989). Hundreds of thousands of these charts, always updated to the latest standards, were distributed to fax users around the world for years. The idea was to provide a reliable and rapid means of testing the equipment and evaluating the quality of the transmission, in light of the new international standards. In this context, the first interaction that most users had with a fax machine consisted in testing its ability to recreate a picture designed by an international committee - a highly curated composition of texts, drawings and photographs on an A4 page.

These charts were more than simple utilitarian devices. It is easy to see that they responded to the graphic idioms and, one may dare say, the aesthetics of their time. For example, even though there is absolutely no relation between the two, there are striking analogies between the fax test chart 167A distributed by the CCITT in 1986 (as Rossi was opening his American office) and a drawing of the Modena Cemetery titled Composition with Saint Apollonia, made in 1977. Both are defined by a play on pure geometries such as pyramids and cubes, a subdivision of the page into precisely framed sections, a repetition of regular patterns, a general representational flatness and systematic shifts of scale. But the most evident correspondence is the one between the photograph of the famous Eastman Kodak secretary, whose picture appeared on a number of test charts, and the painting of Saint Apollonia - the two exceptions in these otherwise abstract compositions, both placed to the left of the axis of symmetry.

Evidently, this is not a formal comparison for its own sake: the point is to show that the process of standardization that allowed the fax machine to become a widespread commodity went hand in hand with the promotion of a specific aesthetic which, through devices like the test charts, entered the houses and 
workspaces of millions of people worldwide. And, as evidenced by the photograph of the Eastman Kodak secretary, this message came with certain highly-charged subtexts regarding broader social phenomena.

The case of Rossi highlights a constant tension between these forces of globalization - with their international systems of rules and regulations - and the limitations typical of any local milieu. For example, the CCITT could not do anything about a fundamental difference: the simple fact that Europeans use pages that are 21 centimeters wide, while for Americans it's 8.5 inches. Because of this divergence in format, it was essential that all fax machines were set up to maintain the scale of the incoming drawing, rather than adjust it according to their own paper size.

As is still the case in most contemporary printing machines, this option was called "Actual Size," as opposed to the other primary printing mode, "Fit to Page." So, not only the transmission of a fax from one place to another implied a form of dematerialization, but also the printing process called for a reflection on the relation between content (drawing) and medium (paper). In order to preserve the all-important dimensional integrity of the fax, the drawing needed to be dissociated from the paper of the receiving machine. In other words, the drawing could not fit to page. Abstracting the drawing from the page required to think about scale in a different way. Both the term "Actual Size" associated with fax machines and the expression "Stessa Scala” used by Adjmi seem to respond to the same logic. Neither of them provided any information regarding the specific dimensions of the object: what mattered was maintaining dimensional consistency throughout the faxing process. As noted by one of Rossi's collaborators in a postscript to a fax sent in 1992, "Beware of the measurements!"18

\section{The analogy-machine}

The rift between the drawing and the page also speaks to how faxing related to the architectural discourse of its time. It's important to underline that this technology operated by scanning and transmitting images through the telephone system, in the form of audio-frequency tones. At the end of the process, the receiving machine interpreted the tones and
18 - Fax sent by Architect Vanni Rizzo to Rossi's Milanese studio, 9 June 1992 - Archive of the Canadian Centre for Architecture (Montreal), Aldo Rossi Fonds: Projects.
Not only the transmission of a fax implied a form of dematerialization, but also the printing process called for a reflection on the relation between content and medium. 
19 - This theme has recently been explored in the exhibition Aldo Rossi: The Architecture and Art of the Analogous City, organized by Daniel Sherer at the Princeton University School of Architecture, in the Winter of 2018.

\section{Faxing was, in effect, an extension of the oral traditional of telephone conversation.}

reconstructed the image, printing a paper copy. So, in a period in which architects were involved in the semiosphere up to their necks and linguistic theory was king, practices like that of Rossi were using a machine that turned drawings into a sound-based language and then back into drawings on the other side of the world. Architecture was literally being sent through the telephone line.

Notably, this was the period in which Marshall McLuhan and Walter Ong addressed the impact of electronic media on the rift between orality and literacy, identifying the emergence of forms of interaction and communication that put forward a "new orality" (McLuhan, 1964; Ong, 1982). As noted by Liz Farrelly, faxing was, in effect, an extension of the oral traditional of telephone conversation: "It's never as static as a piece of typed, proofed, published writing or codified computerized data” (Farrelly, 1994). Even the technical terminology seems to respond to that tradition. For example, in the fax jargon, the initial contact between two machines is known as the handshake - a moment perceived as singing tones, in which the machines check compatibility and set the mode of transmission. And this is just the most noticeable part of a process that is entirely based on turning the signs on a page into continuous analog signals.

From this point of view, the analog technology of the fax machine may also be associated with Rossi's notion of analogy - the core of his theory of architecture. ${ }^{19}$ In the introduction to the American version of The Architecture of the City, Peter Eisenman argued that "the subversive analogues" produced by Rossi relied on two types of transformations: "the dislocation of place and the dissolution of scale” (Eisenman, 1982). Canaletto's veduta of Venice with three Palladian monuments, none of which is actually in Venice, was often referenced in Rossi's writings to explain the mechanism of this analogical design method. In this framework, the geographical transposition of multiple objects was meant to produce an ensemble that could be immediately recognized, even though it was a place of purely architectural references. If early projects like the collage The Analogous City, presented at the Biennale of 1976, were done by copying, cutting and pasting drawings on top of each other, this method took on a new meaning in the last phase of Rossi's 
career, as drawings started to be faxed back and forth between Milan and New York. Even though this convergence went largely unnoticed, faxing allowed many of the concepts that populated Rossi's discourse (and postmodernism at large) to overstep the bounds of theory and interact with the realm of technology, shifting the focus from product to process. The fax was the ultimate analogy-machine.

\section{References}

Agamben, G. (2017), Autoritratto nello Studio, Milano, Nottetempo.

Bartlett, A. (1984), Algebra, the Golden Rectangle and Paper

Sizes, "Journal of College Science Teaching," n. 6, vol. 13, pp. 410-413.

Bell, L. (1994), F'AXis, in L. Farrelly (ed), Urgent Images: The Graphic Language of the Fax, London, Booth-Clibborn Editions.

Bonfanti, E. (1970), Elementi e Costruzione: Note sull'Architettura di Aldo Rossi, “Controspazio,” n. 10, pp. 19-28.

Buren, D. (1979), The Function of the Studio, “October,” vol. 10, pp. 51-58.

Celant, G. (2008), Aldo Rossi Draws in G. Celant, D. Ghirardo, L. Molinari (eds), Aldo Rossi: Drawings, Milano, Skira.

Coopersmith, J. (2015), Faxed: The Rise and Fall of the Fax Machine, Baltimore, Johns Hopkins University Press.

Costantini, P. (ed.) (2016), Luigi Ghirri / Aldo Rossi: Things Which Are Only Themselves, Montreal, Canadian Centre for Architecture - Electa.

Council of Europe (1989), The Fax! Program, Strasbourg, Council of Europe Press.

Davidson, C. (ed.) (1993), Electrotecture: Architecture and the electronic future, "ANY”, n. 3.

Eisenman, P. (1982), Editor's Introduction: The houses of memory - The texts of analogy, in A. Rossi, The Architecture of the City, Cambridge (MA), The MIT Press - Oppositions Books.

Farrelly, L. (1994), Glitch in a digital world, in L. Farrelly (ed.), Urgent Images: The Graphic Language of the Fax, London, Booth-Clibborn Editions.

Ferlenga, A. (ed.) (2002), Aldo Rossi: The Life and Works of an Architect, London, Konemann.

Fishman, D., King, E. (1988), The Book of Fax: An Impartial Guide to Buying and Using Facsimile Machines, Chapel Hill, Ventana Press.

Fondazione Aldo Rossi (2018), Biografia di Aldo Rossi [Online]. Available at: https://www.fondazionealdorossi.org/ biografia/ [Accessed: 1 May 2019].

Forster, K. (1990), Aldo Rossi's architecture of recollection: The silence of things repeated or stated for eternity, in The 
Pritzker Architecture Prize, 1990: Presented to Aldo Rossi, Los Angeles, Jensen and Walker.

Ghirardo, D. (2019), Aldo Rossi and the Spirit of Architecture, New Haven, Yale University Press.

Harwood, J. (2003), The white room: Eliot Noyes and the logic of the information age interior, "Grey Room”, n. 12, pp. 5-31.

Jones, C. (1995), Machine in the Studio: Constructing the Postwar American Artist, Chicago, University of Chicago Press.

Kinross, R. (2009), A4 and Before: Towards a Long History of Paper Sizes, Wassenaar, Netherlands Institute for Advanced Study.

Latour, B. (2010), The migration of the aura or how to explore the original through its facsimiles, in T. Bartscherer (ed.), Switching Codes, Chicago, University of Chicago Press.

Lobsinger, M. (2002), That obscure object of desire: Autobiography and repetition in the work of Aldo Rossi, "Grey Room", n. 8, pp. 38-61.

Martin, R. (2003), The physiognomy of the office, in R. Martin, The Organizational Complex: Architecture, Media and Corporate Space, Cambridge (MA), The MIT Press.

McConnell, K. et al. (1989), Fax test charts, in K. McConnell et al., Fax: Digital Facsimile Technology and Applications, Norwood, Artech House.

McLuhan, M. (1964), Understanding Media: The Extensions of Man, New York, Signet Books.

Melia, P. (ed.) (1995), David Hockney, Manchester, Manchester University Press.

Ong, W. (1982), Orality and Literacy: The Technologizing of the Word, New York, Methuen.

Ornaghi, N., Zorzi, F. (2015), A conversation with Arduino Cantàfora, "Log”, n. 35, pp. 85-96.

Poynor, R. (1997), Profile: Paul Elliman, “Eye”, vol. 7, n. 25. Szacka, L. (2014), Aldo Rossi, Bruno Reichlin, Fabio Reinhart and Eraldo Consolascio: ETH Zurich, "Radical Pedagogies” [Online]. Available at: http://radical-pedagogies.com/ search-cases/e08-eth-zurich/ [Accessed: 1 May 2019].

Van Meel, J. (2000), The European Office: Office Design and National Context, Rotterdam, 010 Publishers.

Warhol, A. et al. (1986), Global Art Fusion, Bern, Art Fusion Edition. 


\section{Graphics}

Tapiro Design - Venezia / Dalila Tondo - Torino

(C) 2019 Rosenberg \& Sellier

Published under the Attribution-NoDerivatives 4.0

International Creative Commons license

\section{(cC)}

Every effort has been made to trace or contact all copyright-holders.

The publisher will be pleased to make good any omissions

or rectify any mistakes brought to his attention

at the earliest opportunity.

\section{Publisher}

LEXIS Compagnia Editoriale in Torino srl

via Carlo Alberto 55

I-10123 Torino

rosenberg\&sellier@lexis.srl

\section{0 subscription price list}

(issues \#06 \#07)

$\begin{array}{llll} & \text { Italy } & \text { Europe } & \text { World } \\ \text { paper edition } & € 45,00 & € 60,00 & € 75,00 \\ \text { digital edition } & € 18,00 & € 18,00 & € 18,00 \\ \text { paper + digital edition } & € 52,00 & € 67,00 & € 82,00\end{array}$

For subscriptions and any further information:

abbonamenti@rosenbergesellier.it

Single issues and articles can be purchased on

www.rosenbergesellier.it

Resenbery \& Seller è un marchio registrato utilizzato per concessione della società Traumann s.s.

Iscrizione al Registro Stampa del Tribunale di Torino n. 38/2017 del 17/07/2017

Direttore responsabile: Antonio Attisani 

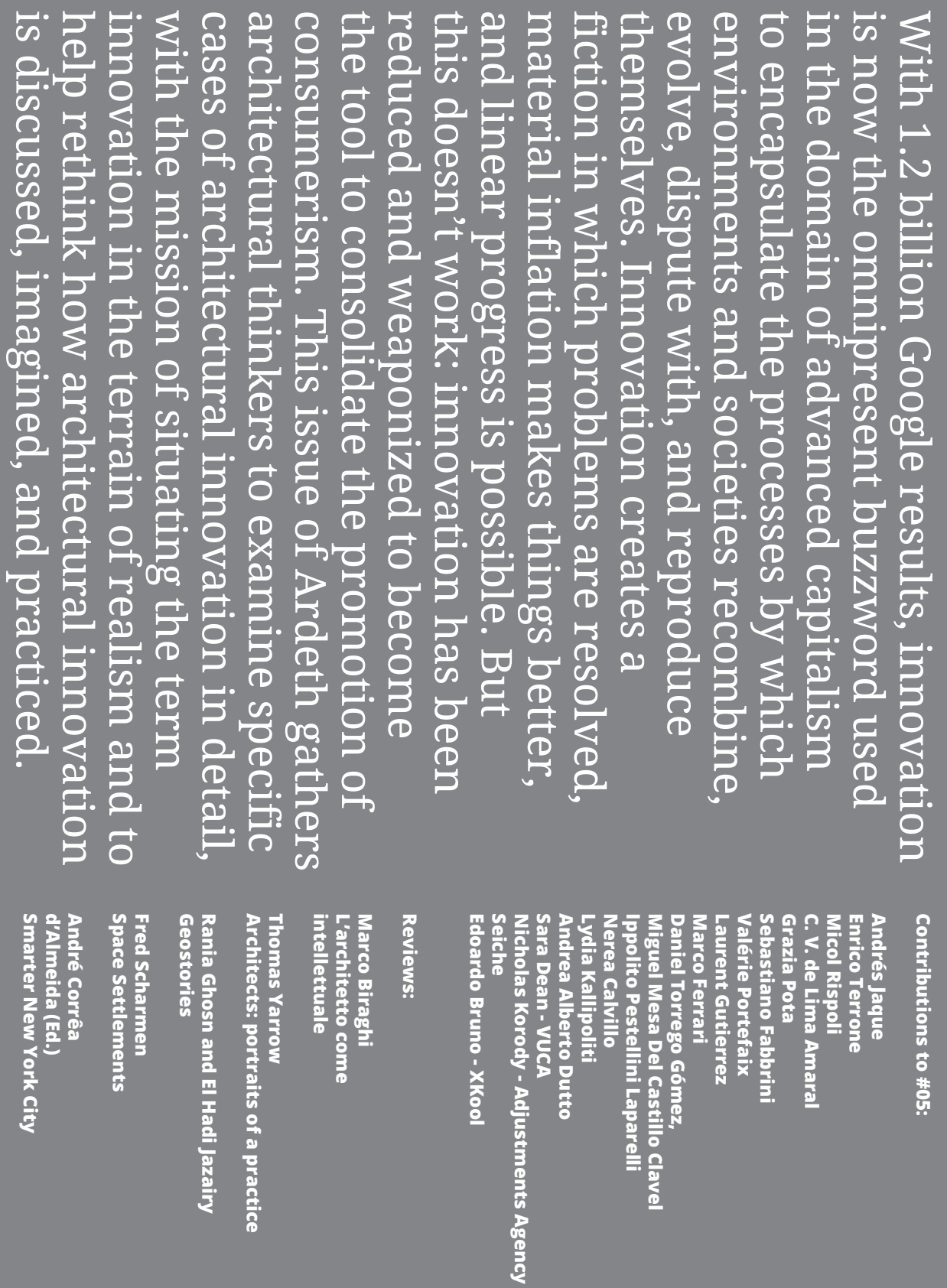